\title{
OPTIMIZATION IN WATER RESOURCES AT DRY WEATHER CONDITIONS BEFORE AND AFTER THE DAM FAILURE BY USING DUMMY VARIABLE REGRESSION APPROACH
}

\author{
H. A. Torabi ${ }^{\text {a }}$, M. Najarchi ${ }^{\text {b, }}{ }^{*}$, H. Mazaheri ${ }^{c}$, R. Jafarinia ${ }^{\text {a }}$, M. Izadikhah ${ }^{\text {d }}$ \\ ${ }^{a^{*}}$ Department of Water Engineering, Arak Branch, Islamic Azad University, Arak, Iran, E-mail: m-najarchi@iau-arak.ac.ir \\ ${ }^{\mathrm{b}}$ Department of Civil Engineering, Arak Branch, Islamic Azad University, Arak, Iran \\ ${ }^{c}$ Department of Chemical Engineering, College of Engineering and Technology, Arak Branch, Islamic Azad University, Arak, Iran \\ ${ }^{\mathrm{d}}$ Department of Mathematics, College of Science, Arak Branch, Islamic Azad University, Arak, Iran
}

Received: 14.12.2020 / Accepted: 04.01.2021 / Revised: 23.02.2021 / Available online: 31.05.2021

DOI: 10.2478/jaes-2021-0009

KEYWORDS: Dam failure, Dummy variable, linear programming, optimization, water supply.

\begin{abstract}
:
One of the direct economic consequences of dam failure (DF) is that water supply for irrigation is affected and incomes of the agriculture sector (AS) are reduced. The main purpose of this study is to apply a linear programming model (LPM), which, the objective function of the model was set to maximize the income function of the region AS with accessible water sources and function of crops production before and after the DF by using dummy variable (DV) regression models to optimize water supply for irrigation. The results obtained indicate that the consumption of surface water(SW) and groundwaters (GW), before the DF has not been optimized, as there are $15.5 \%$ source loss in SW and $14.5 \%$ in GW. After the DF, the allocation of SW in the best possible situation of access to SW sources is independent of the model input. It has a fixed value equivalent to 86 million cubic meters (MCM), which indicates a $116 \%$ decrease in comparison with the optimized value. Total accessible water sources are decreased by $36 \%$ and using GW is $15 \%$ more than an average long period time. A based on the finding from this research and its comparison with previous studies, this model is appropriate for water supply programming after DF and for dry weather Conditions.
\end{abstract}

\section{INTRODUCTION}

Water has always been a limiting factor in agriculture. nowadays more than $80 \%$ of the world's agriculture is through dry cultivation. The influence of water resources on economic fertility and social welfare is significant, as all economic and social activities are largely based on supply and quality of drinkable water. More than half of earth's large river systems (LRS) are affected by dams (Christer, 2005). Many of these basins are strongly impacted by fragmentation, Europe has the highest total basin area that is strongly impacted (74\%) by the reduction in water resources, but all continents have a substantial percentage of strongely impacted LRS area (Christer, 2005) More than $80 \%$ of water is used for the irrigation of the agriculture sector and less than $20 \%$ is assigned to municipal, industrial and other consumptions as a global average. However in Iran those are 93\% and $7 \%$ (Hassani, 2017) SW and dam reservoirs are the main sources of sweet water supply. Destruction of dams and its floods not only lose the construction investment but also cause heavy and uncompensable losses to villages, cities, agriculture lands, industrial installations, roads and other construction plans in the shoal, which has great social, political, environmental and economic consequences (US Water Resources Council, 2012).
Mortality caused by a dam failure flood is determined by the characteristics of the flood (depth and velocity) and the possibilities for warning (Jonkman, 2008).

Dam failures result in loss of human life and cause owner's loss and community loss (economic loss and environmental damage) the assets that will be affected by a dam failure require a brief description of the inundation area.

These assets can be combined into two groups, direct loss and indirect loss. The first group includes residential property, commercial and industrial property, public property, infrastructure and those assets that exist because of the project (i.e., dam, subsidiary facilities diversion, and dams downstream). The second group includes societal consequences and environmental damages. The direct loss upon failure can be estimated by a survey of the inundation area or using the census data. Loss of life is a very important factor in Benefit-cost analysis approach based on the life quality index (Huai, 2013). According to American National Infrastructure Protection Plan (NIPP) report, the economic consequences of DF are divided into direct and indirect consequences. Direct economic consequences are those which are caused directly by DF flood. Losses of income or profit related to products and services

\footnotetext{
* Corresponding author: Mohsen Najarchi, Associte Professor Department of Water Science Engineering, Islamic Azad University of Arak, Iran Email: m-najarchi@iau-arak.ac.ir
} 
resulting from the dam construction are also among the direct costs of DF (HSPD, 2011). One of the most important direct economic consequences of DF is that irrigation water supply will be affected, and as a result, agriculture incomes are decreasedSome studies have been already done concerning the optimization of water sources allocation for water supply in AS, industry, and potation in normal conditions of dam operations, and also a calculation of economic losses amount caused by DF. When the water supply is faced with limitations, concerning product choice and irrigation level, we should take actions based on the profitability of crops and according to the effects caused by water shortage (Doorenbos, 1979 and English, 1982). The optimization methods divide into two parts:classic methods based on mathematics, and numeric research methods (direct and indirect). In both classic (e.g .linear planning) and numeric methods, the objective function (OF) should be dominant and derivative (Rao, 1984). For predicting loss of life (LOL) from severe flooding events, an expression for LOL in terms of warning time (WT), the size of the population at risk (PAR), and the forcefulness of the floodwaters (Force) is derived from the historical record of dam failures and flash flood cases via logistic regression use of DV in Testing for Equality between Sets of Coefficients in Linear Regressions, when WT is coded dichotomously e.g zero for WT $<1.5 \mathrm{hr}$ and one for WT $1.5 \mathrm{hr}$ (Michael and Gary, 1993 and Frizzone, 1997) to developed a separable LPM, considering a set of technical factors That may influence the profit of an irrigation project. The model presents an OF that maximizes the net income and specifies the range of water availability. It is assumed that yield functions in response to water applications are available for different crops and describe very well the water-yield relationships. The LPM was developed genetically, so that, the rational use of the available water resource could be included in an irrigation project, Specific equations were developed and applied in the irrigation project Senator Nilo Coelho, located in Petrolina - Brazil Based on the water-yield functions considered, cultivated land constraints, production costs and products prices. Ghahraman et al. popularized the optimization model algorithm of water allocation to agriculture plants with limited water amount to a single purpose reservoir (Ghahraman, 2004). In this way, they codified the optimization standard of water dropping for a single purpose reservoir. Kumar (Kumar, 2012) proved that there is not a meaningful difference between the genetic algorithm model as a new model and LPM in water sources management and presentation of results for a specific subject .Yavari et al (Yavari, 2005) estimated the production function (PF) of Iran AS using DV from 1980 to 1988 (coincided with Iraq-Iran war). The results derived from the calculation of natural SW and GW efficiencies show that marginal efficiency and average natural SW and GW has been different and with meaningful function coefficients, in comparison with the time in which war conditions were not considered in the PF. Issue of The American Stutisticiun (2012) had shown how the DV 1 and 0 can be used as an alternative to the standard analysis of variance and covariance techniques and the Chow test. That discussion was, however, confined two linear regressions and to two variables-one dependent and one independent. The purpose of American Statistician was to generalize the DV technique to more than two linear regressions in more than two variables and to point out some of the problems involved in the actual application of the technique. Hasan et al (Hasan, 2015) at Florida university of America studied the LPM for optimization of water supply for irrigation of Bangladesh agricultural areas. Alok Kumar (Kumar, 2014) estimated the price and family costs sensitivity to energy consumption in the household sector of urban and rural areas, with DV regression attitude towards measuring energy and strain in India. He used the National Sample Survey Organization (NSSO) data of 2009-2010 and defined DV in the regression equation, which was 0 for villages and 1 for cities. The main purpose of this research is to present an LPM to allocate optimized SW sources, using the DV technique in the estimation of income and agriculture crops function considering a set of affecting production factors through maximizing the income function in AS. Known methods for assessment of DF and resulting in its floods consequences on the environment are faced with some limitations. These limitations are not only related to implementation and fiscal problems, but also mutual communication understanding of governing processes on the systems is one of the chief limitations. Calculation of economic losses, related to the DF phenomenon, a consequent flood is very difficult and sometimes impossible due to its multi-layer effects, wide range and quality nature. Use of DV as a technique and approach, in measuring economic consequences of quality variables for calculation of income function (IF) and agriculture producing function (APF) in a water catchment basin is important and resolver, for the programming of politicians in different possible scenarios after assumptive DF. According to past researches, the most have published articles the investigation of dam failure considering the impact of the dam on downstream lands with the perspective of optimization and based on the approach to using dummy variables not done. Therefore, this paper has been investigated for the first time in one of Iran's dams. Further other advantages of this method are compared to other methods, such as simulating less cost and faster access to acceptable results for resource management planning. In addition, this methodology is based on real data occurring in various agricultural, industrial, and urban sectors, and is highly accurate when accessing regression model data and linear programming model constraints.

\section{METHODOLOGY AND MATERIALS}

The location and specifications of the water basin and Mamloo Dam, Varamin water basin, which is one of the Iranian agricultural areas, has an area of 1250 square kilometers $\left(\mathrm{Km}^{2}\right)$. As Varamin is near Tehran, it is of a special position in the agriculture sector of Iran. Longitude: $52^{\circ}-42$, from the beginning of the cone of Jajrood river. Latitude: $35^{\circ}-28$, from the beginning of the cone of the Jajrood river Altitude from sea level: about 1100 meters $(\mathrm{M})$. The plain height in the border with the salt desert: about $950 \mathrm{M}$. The average length: equal to 45 kilometers $(\mathrm{Km})$.

The average width: equal to $27 \mathrm{Km}$ Jajrood river and its branches are the main sources of the basin surface water supply in the south part of the Alborz mountains. Mamloo dam has a water basin with an area of $1750 \mathrm{Km}^{2}$. The dam is located 2 kilometers from the junction of Damavand and Jajrood rivers. The width of the river bed is 200 meter. Table 1 presents the properties, specifications and storage capacity of Mamloo dam and figure 1 shows the map of Mamloo Dam.

\begin{tabular}{|c|c|c|c|}
\hline Type & $\begin{array}{c}\text { Clay or } \\
\text { earth core }\end{array}$ & Basin (area) KM² & 1750 \\
\hline Crest length (M) & 807 & $\begin{array}{c}\text { Average input in } \\
\text { long term annually } \\
\text { (M.C.M) }\end{array}$ & 268 \\
\hline
\end{tabular}




\begin{tabular}{|c|c|c|c|}
\hline $\begin{array}{c}\text { Level of crest } \\
\text { from the sea level } \\
\text { (MM) }\end{array}$ & 1308 & $\begin{array}{c}\text { normal Water } \\
\text { level (M) }\end{array}$ & 1303 \\
\hline $\begin{array}{c}\text { The core } \\
\text { embankment } \\
\text { volume (M.C.M) }\end{array}$ & 1.05 & $\begin{array}{c}\text { Normal level in } \\
\text { the reservoir (M) }\end{array}$ & 250 \\
\hline $\begin{array}{c}\text { Total volume of } \\
\text { the dam body } \\
\text { (M.C.M) }\end{array}$ & 7.34 & $\begin{array}{c}\text { Minimum water } \\
\text { level in reservoir } \\
\text { (M) }\end{array}$ & 1257 \\
\hline $\begin{array}{c}\text { Fundament } \\
\text { height (M) }\end{array}$ & 90 & $\begin{array}{c}\text { Normal level in } \\
\text { the surface } \\
\left.\text { reservoir (KM }{ }^{2}\right)\end{array}$ & 7.76 \\
\hline
\end{tabular}

Table 1. Specifications and Storage Capacity of Mamloo Dam,Tehran, IRAN

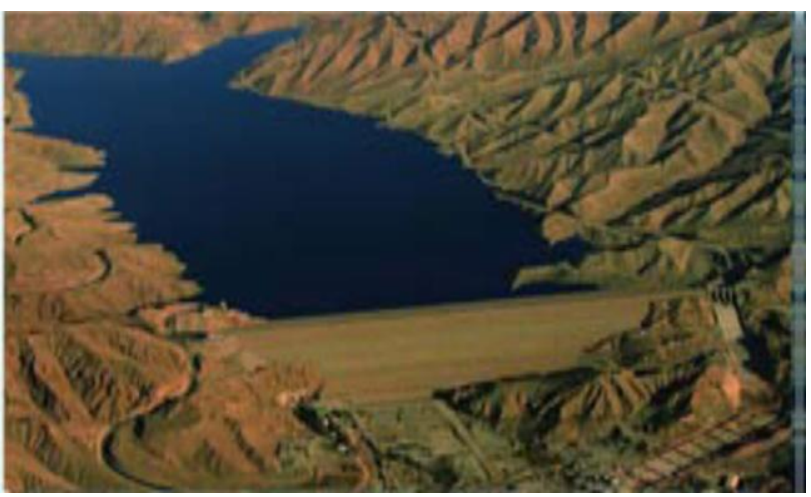

Figure 1. The dam of Mamloo (Google Earth, 2017)

\subsection{Data resources}

Statistic reports of 1990 - 2016 water basin including water cultivation area, cultivation patterns, crops efficiency, capital, labor, natural SW and GW consumption of the AS area divided by agricultural crops, amount of crops production and income (in Rials), agricultural income as a whole until 2040 as per prepared and classified by the ministry of Agriculture and the ministry of Power are as follows:

1. Extraction and collection of data related to water needed for crops irrigation (agriculture crops of the understudy area), divided by each crop, for every months of 1990-2016, and also the predicted information till the year 2040 .

2. Extraction and collection of accessible amounts of natural SW and GW in the area from 1990 to 2040.

3. Calculation of the information related to the allocated water from Mamloo dam in order for agricultural, municipal and industrial uses from 2010 to 2016.

4. Estimation and determination of the best fitting of the income function and 7 different crops including wheat, barley, cucumber, tomatoes, alfalfa (hey) and onions, which are considered as the holders of $98 \%$ of agricultural income of the area, with LPM with the help of econometrics, E views 8 software in before DF.

5. Estimation and determination of the best fitting of the income function and 7 different crops including wheat, barley, cucumber, tomatoes, alfalfa (hey) and onions, which are considered as the holders of $98 \%$ of agricultural income of the area, with LPM with the help of econometrics, E views 8 software in after DF using DV.

6. Using LNGO 14 software in order To maximize the objective income function (OIF) with LPM, in two situations: normal operation of the dam and definition of different scenarios for acritical status of supposed DF.

7. Analyzing and comparing the results of maximizing OIF before and after the DF, from the allocation of optimized water consumption in AS viewpoint.

8. Comparison between model results and previous research methods.

\subsection{Econometrics}

A regression model such as consumption function in abnormal and normal periods include both quantity and quality variables. In this regression model, the dependent variable not only depends on the quantity variable but also depends on the quality variable as well. Fig 1 and fig 0 are attributed to wartime and peacetime periods respectively. The variables which are specified in this way, are called dummy, binary or qualitative variables.

This study explains the use of DV as a technique for the estimation of agriculture crops function and also income +function of water basin AS after the DF with the help of econometric models and EViews8 software.

function form of Cob and Douglas is one of the most widespread function forms, used in empirical estimation especially in the agriculture sector.

In this paper, regarding to meaningfulness of coefficient patterns, below-mentioned cases have been estimated: maximum amount of statistic verisimilitude logarithm, minimum standards of Akaike info criterion and Chwarz and Schwartz and Bin criterion Hannan-Quin criterion, accuracy of Ramsey test examination of omitted variables, examination of non-related variables, examination of t-statistic, and DurbinWatson stat model. According to the results of Ramsey reset test, function form of the transcendentalmodel is used.

Function form of Transcendental model is as follows:

$$
\mathrm{Y}_{\mathrm{t}}=\mathrm{A} \sum_{\mathrm{i}=\mathbb{1}}^{\mathrm{n}} \mathrm{X}_{\mathrm{i}}^{\beta_{\mathrm{i}}} \mathrm{e}^{\mathrm{Y}_{\mathrm{I}} \mathrm{x}_{\mathrm{i}}}
$$

In this function form, e is the Logarithm base with the function form of independent variables that have been added to Cob and Douglas function as the power, in which $\beta_{i} g Y_{1}$ are fixed and the mentioned function is changed to linear form through logarithm operation. Assumptions of normal classic regression models are truthful in the function and can be estimated by Ordinary Least Squares .

$\operatorname{Ln} Y_{i}=\beta_{0}+\sum_{i=1}^{n} \beta_{i} \ln X_{i}+\sum_{i=1}^{n} Y_{i} X_{i}$ 
$\mathrm{LnY}_{1}=\beta_{0}+\beta_{1} \operatorname{lnx}_{1}+\beta_{2} \operatorname{lnx}_{2}+\cdots+\beta \operatorname{lnx}_{1}+Y_{1} X_{1}+\cdots+\mathrm{YX}_{1}+\varepsilon_{\mathrm{I}_{1}}$

Explanatory independent variables including: $\mathrm{X}_{1}=$ groundwaters, $\mathrm{X}_{2}=$ surface waters are in terms of M.C.M, $\mathrm{X}_{\mathrm{a}}=$ labour is in terms of 1000 people/hectare, $\mathrm{X}_{4=}$ capital is in terms of Milliard Rials; $X_{5}=$ cultivation area is in terms of hectare, and $\mathrm{Y}_{\mathrm{i}=}$ the dependent wariable is in terms of Milliard Rials (or kg)

The crops PF and income function (IF) of the area in normal conditions of dam operations are estimated as follows:

$$
\begin{aligned}
& \operatorname{Ln~}_{i}=\beta_{0}+\beta_{1} \operatorname{lnx}_{1}+\beta_{2} \operatorname{lnx}_{2}+\cdots+\beta_{5} \operatorname{lnx}_{5}+Y_{1} X_{1}+ \\
& { }^{\prime \cdots}+Y_{5} X_{5}
\end{aligned}
$$

For the DF condition, the following function was considered in order to determine the function of crops and IF,

$$
\begin{aligned}
& \operatorname{Ln} Y_{i}=\beta_{\mathrm{n}}+\beta_{1} \operatorname{lnx}_{1}+\beta_{2} \operatorname{lnx}_{2}+\cdots x+\beta_{5} \operatorname{lnx}_{5}+Y_{1} X_{1}+ \\
& { }_{n x}+Y_{5} X_{5}+D_{t}
\end{aligned}
$$

in which $\mathbb{D}_{t}$ is a $\mathrm{DV}$ and is equal to one $\left(\mathbb{D}_{t}=1\right)$ at the time of $\mathrm{DF}$, otherwise, it is equal to zero $\left(\mathrm{D}_{\mathrm{t}}=0\right)$.

\subsection{Linear Programming Model}

The structure of the programming is as follows :

objective function Provisions formation using a series of equations or non-equations Considering non-negative provision If $\mathrm{X} 1, \mathrm{X} 2, \ldots \mathrm{Xn}$ are deciding variables, the intended standard which is called as $\mathrm{OF}$,is defined as belows (6)

$$
\mathrm{F}(\mathrm{X})=\mathrm{C}^{\mathrm{T}} \cdot \mathrm{X}=\mathrm{C}_{1} \mathrm{X}_{1}+\mathrm{C}_{2} \mathrm{X}_{2 \ldots \ldots}+\mathrm{C}_{\mathrm{n}} \mathrm{X}_{\mathrm{n}}
$$

In which $\mathrm{C}_{1}, \mathrm{C}_{2}, \ldots \mathrm{C}_{\mathrm{n}}$ are real numbers and $\mathrm{C}^{\mathbb{I}}$ is the transposed vector of C. In LPM, all decision variables are a non-negative and standard form of each LPM problem which can be as belows :

$$
\text { MAX Z }=C_{1} X_{1}+C_{2} X_{2}+\cdots+C_{n} X_{n}
$$

Subject to:

$$
\begin{aligned}
& a_{11} X_{1}+a_{12} X_{2}+\cdots+a_{1 n} X_{n} \leq b_{1} \\
& a_{21} X_{1}+a_{22} X_{2}+\cdots+a_{2 n} X_{n} \leq b_{2} \\
& a_{m 1} X_{1}+a_{m 12} X_{2}+\cdots+a_{m n} X_{n} \leq b_{m} \\
& X 1, x 2 \ldots X n \geq 0
\end{aligned}
$$

The relations (7) to (9) can be considered as following relations (10) and (11):

Max or Min $\mathrm{z}=\mathrm{C}^{\mathrm{T}} \cdot \mathrm{X}$

St : $\mathrm{AX}=\mathrm{b} ; \mathrm{X} \neq 0$

In these relations:

$\mathrm{Z}$ : objective function

$\mathrm{C}: \mathrm{n}$ vector, which is a dimension of OF coefficients

$\mathrm{X}: \mathrm{n}$ vector, a dimension of decision-making variables

B: $\mathrm{m}$ vector, a dimension of right side coefficients, showing accessible sources

A: $m * n$ matrix , one of the provisions coefficients

T: matrix transposed operator
In LPM, production functions of each crop are taken into consideration in both conditions with the other production factor and politicized amounts of agriculture crops as a limited model (Kassahun, 2014). The optimized amount of consumption water for the total area of agriculture crops is determined by maximizing the income.

\section{RESUTLS AND DISCUSSION}

\subsection{Estimation of the Income Function (IF) of AS before DF} status

The best fitness of the Transcendental area of IF before the DF by using Eviews 8 software was estimated to create relations between inputs and outputs.

$\mathrm{LNY}=3.38332-0.5354637 * \mathrm{LNX} 1-0.2533126 * \mathrm{LNX} 2+$ $0.0813253 *$ LNX3 $+1.2742051 *$ LNX4 $-0.000176446 * X 4$

According to the results mentioned in table 2, coefficients of capital variables, the logarithm of groundwater and surface waters, labor and logarithm capital are in the level signification of 0.05 regarding prob column values.

F statistic shows that the whole regression model is meaningful and usable. $\mathrm{R}^{2}$ statistic is equal to $99 \%$, which shows that $99 \%$ of dependent variable changes (any) is described by independent variables.

\begin{tabular}{|c|c|c|c|c|}
\hline Variables & Coefficient & Std. Error & t-Statistic & Prob. \\
\hline $\mathrm{C}$ & 3.383323 & 1.189961 & 2.743221 & 0.0100 \\
\hline $\mathrm{x} 4$ & -0.000176 & 0.000104 & -1.693747 & 0.1058 \\
\hline $\ln 1$ & -0.535464 & 0.173345 & -3.089011 & 0.0058 \\
\hline $\ln 2$ & -0.253313 & 0.119427 & -2.121077 & 0.0466 \\
\hline $\ln 33$ & 0.081325 & 0.037397 & 2.174666 & 0.0418 \\
\hline $\ln 4$ & 1.274206 & 0.043106 & 29.55977 & 0.0000 \\
\hline R-squared & \multicolumn{5}{|c|}{0.995941} \\
\hline $\begin{array}{c}\text { Adjusted R- } \\
\text { squared }\end{array}$ & 0.994926 \\
\hline S.E. of regression & 0.110226 \\
\hline Sum squared resid & \multicolumn{5}{|c|}{0.242998} \\
\hline Log likelihood & \multicolumn{5}{|c|}{23.85400} \\
\hline F-statistic & \multicolumn{5}{|c|}{0.000000} \\
\hline Prob (F-statistic) & \multicolumn{5}{|c|}{2.469764} \\
\hline $\begin{array}{c}\text { Durbin-Watson } \\
\text { stat }\end{array}$ & \multicolumn{5}{|c|}{} \\
\hline
\end{tabular}

Table 2. IF estimation of AS results before DF status

\subsection{Estimation of Income Function(IF) of AS after DF status}

The best fitness of the transcendental area IF for after DF status by using Eviews 8 software was estimated to create relations between inputs and outputs by using the DV approach.

$\mathrm{LNY}=1.167627+0.230648 * \mathrm{Dt}+5.130783 \mathrm{e}-06 * \mathrm{X} 3-$ $0.00028585 * \mathrm{X} 4-0.22473809 * \mathrm{LNX} 1+1.117063 * \mathrm{LNX} 4$

The results of this pattern estimation are shown in table 3 .

\begin{tabular}{|c|c|c|c|c|}
\hline Variables & Coefficient & Std. Error & t-Statistic & Prob. \\
\hline C & 1.167627 & 0.377506 & 3.09307 & 0.0057 \\
\hline
\end{tabular}




\begin{tabular}{|c|c|c|c|c|}
\hline $\mathrm{x} 3$ & 5.13E-06 & $1.86 \mathrm{E}-06$ & 2.75322 & 0.0123 \\
\hline $\mathrm{x} 4$ & -0.000286 & 0.000117 & -2.43879 & 0.0242 \\
\hline $\ln x 1$ & -0.224738 & 0.069777 & -3.56196 & 0.0020 \\
\hline $\ln x 4$ & 1.177063 & 0.037137 & 31.6952 & 0.0000 \\
\hline $\mathrm{Dt}$ & 0.230048 & 0.109625 & 2.0985 & 0.0488 \\
\hline R-squared & \multicolumn{4}{|c|}{0.996252} \\
\hline $\begin{array}{c}\text { Adjusted R- } \\
\text { squared }\end{array}$ & \multicolumn{4}{|c|}{0.995315} \\
\hline S.E. of regression & \multicolumn{4}{|c|}{0.105917} \\
\hline $\begin{array}{l}\text { Sum squared } \\
\text { resid }\end{array}$ & \multicolumn{4}{|c|}{0.224367} \\
\hline Log likelihood & \multicolumn{4}{|c|}{24.890990} \\
\hline F-statistic & \multicolumn{4}{|c|}{1063.199000} \\
\hline Prob(F-statistic) & \multicolumn{4}{|c|}{0.000000} \\
\hline $\begin{array}{c}\text { Durbin-Watson } \\
\text { stat }\end{array}$ & \multicolumn{4}{|c|}{2.270223} \\
\hline
\end{tabular}

Table 3. IF estimation of AS results after DF status

According to the results mentioned in table 3, coefficients of capital and labour variables, logarithm of GW, logarithm of capital and DV are in the level of 0.05 signification regarding prob column values. F statistic shows that the whole regression model is meaningful. R Squre-statistic is equal to $99 \%$, which shows that $99 \%$ of dependent variable changes (any) is described by independent variables.

According to the mentioned methodology articles, transcendental function before and after the DF for each crop is estimated separately which are 14 functions in total, and are used as limiting functions in LPM in LINGO software.

The results of classic assumptions investigation including multicollinearity and heteroskedastic and also normality of residuals sentences did not affect the estimated models of income and crops functions.

The results of the t-Statistic investigation showed that all the estimated coefficients for all income functions, production of crops functions( PFs) in the AS, both normal and abnormal operations (supposing dam failure and using DV in functions) by OLS method are meaningful.

The results of the F-statistic investigation revealed that all the regression models related to IFand PFs in the AS before and after the DF by OLS method are meaningful.

The results of the R Squre-statistic investigation showed that in the functions of income and crops production of the agriculture area before and after the DF (supposing dam failure) estimation by OLS method, dependent variable changes (any) by independent variables are described with a very high percentage (mostly more than 97\%).

Durbin-Watson statistic, for recognizing Autocorrelation by OLS method of all estimated functions indicates the in Autocorrelation (if $\mathrm{DW}=2$, non-Autocorrelation; if $\mathrm{DW}=0$, complete positive Autocorrelation is available; if $\mathrm{DW}=4$, means complete negative Autocorrelation), thus the raters are the best linear unbiased estimation (BLUE) and efficient.

\subsection{Allocation of the Optimized Water Sources Before and After the Dam Failure}

The results of LPM solution by LINGO 14 software for the dam normal operation and different scenarios in dam failure for the year 2011 (generable for all periods) are presented in table 4 in order to the allocation of optimized SW and GW sources with following assumptions.

3.3.1. LPM for the allocation of optimized water sources in AS under normal dam operations in 2011:

MODEL:

MAX $=3.283323-0.53546 *$ LNX1 $-0.25331 *$ LNX2 +

$0.08132 * \mathrm{LNX} 3+$

$1.2102051 * \mathrm{LNX} 4+0 * \mathrm{LNX} 5+0 * \mathrm{X} 1+0 * \mathrm{X} 2+0 * \mathrm{X} 3$

$0.000176446 * \mathrm{X} 4+0 * \mathrm{X} 5$

St:

1) $\ln x i<=A_{\tilde{i}}$; 2) $\mathrm{Xi}<=B_{\tilde{i}}$; 3) $\ln \mathrm{Xi}>=0$; 4) $\mathrm{Xi}>=0$;

5)

$\operatorname{Ln} Y_{i}=\beta_{0}+\beta_{1} \operatorname{lnx}_{1 \mathrm{i}}+\beta_{2} \operatorname{lnx}_{2 \mathrm{i}}+\cdots+\beta_{5} \operatorname{lnx}_{5 \mathrm{i}}+Y_{1} X_{1 \mathrm{i}}+\cdots+$

$\mathrm{Y}_{5} \mathrm{X}_{5 \mathrm{i}}$

: 6) $\mathrm{ZiN}>=C_{i}$

END.

3.3.2. LPM for optimizing water sources allocation in AS related to after Dam Failure in 2011:

MODEL:

$\mathrm{MAX}=1.1696+0.230648 * \mathrm{DT}+0 * \mathrm{x} 1+0 * \mathrm{x} 2+5.130783 \mathrm{e}-06 * \mathrm{X} 3$ $-0.00028585 * X 4+0 * x 5-0.20473809 * \operatorname{LNX} 1+0 * \ln \times 2+0 * \ln \times 3+$ $1.107063 * \mathrm{LNX} 4+0 * \ln \times 5$;

St:

1) $\ln x i<=A_{\tilde{i}}$; 2) $\mathrm{Xi}<=B_{\tilde{i}}$; 3) $\ln \mathrm{Xi}>=0$; 4) $\mathrm{Xi}>=0$; 5) $\mathrm{DT}=1$

6)

$\operatorname{Ln} Y_{i}=\beta_{0}+\beta_{1} \operatorname{lnx}_{1 i}+\beta_{2} \operatorname{lnx}_{2 i}+\cdots+\beta_{5} \operatorname{lnx}_{5 i}+Y_{1} X_{1 i}+$

$=0+Y_{5} X_{5 i+D t}$

; 7) $\mathrm{ZiN}>=C_{i}$

END.

$\boldsymbol{A} \boldsymbol{i}$ and $\mathrm{B} \boldsymbol{i}$ are fixed $\boldsymbol{Z} \boldsymbol{i} \boldsymbol{N}$ is the amount of crops in normal status, respectively. $\mathrm{Ln} \mathrm{Yi}$ is the crop production function of crop i. The function Results the allocation of the optimized SW and $\mathrm{GW}$, before and after the dam failure

\section{CONCLUSIONS}

Assuming DF in the best behaviour, Total amount of accessible water sources of AS in critical condition, decreases by $36 \%$ in average in comparison to before non-optimum DF behaviour. this result accords with previous studies such as NIPP report findings as per flood studies resulted.

from failures in national city keystone with HAZUS-MH software and developed model C GS according to GS data for earth dam reservoir, which is equal to 25\% (HSPD, 2011). This results are also in good accordance with Ashofteh which studied on the Gharanghu multi-purpose reservoir system (East Azerbaijan, Iran). Their studies revealed that efficiency indexes (EIs) are affected by climate change. the effects of climate change on reservoir inflow, as well as changes in the demand volume over a time interval of 30 years (2040-2069) were also reviewed. Simulation results showed that the long-term average monthly inflow is decreased by about $25 \%$ during climate change in comparison to the baseline 1971-2000 (Ashofteh, 2017). As there are $15.5 \% \mathrm{SW}$ waste sources and $14.5 \% \mathrm{GW}$ waste sources, shows that the consumption of GW (432 MCM) and SW (222.6 MCM) in the normal status of dam operations 
has not been optimum. Meanwhile As a result of non-optimized use of production factors especially accessible water sources, AS income has been reduced by $34 \%$.

Regarding the scenarios no. 3, 4, and 5 of table 4and Figure 2, in which accessible $\mathrm{SW}$ has been considered in sequence as $45 \%, 50 \%$, and $65 \%$ of average long term period of the region (262 MCM), it is observed that in DF assumption, the allocation of optimized SW, even in the best possible accessible surface water amount, is independent of the input and has a fixed amount of $89 \mathrm{MCM}$. Figure 2 shows that at $188 \mathrm{MCM}$, in comparison to the optimized model before DF status, allocation water decreases. In other words, due to the lack of a dam reservoir after dam failure, we cannot use the accessible SW amounts for AS consumptions.

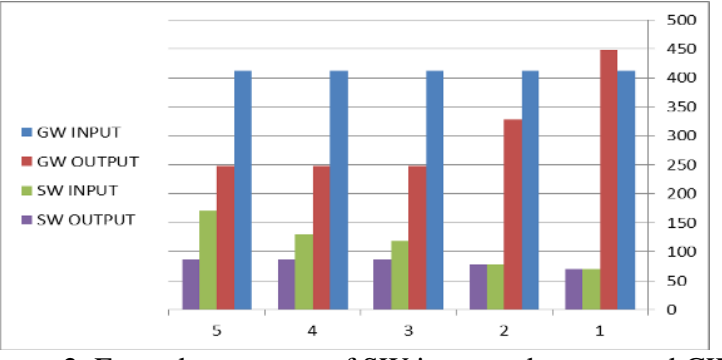

Figure 2. Exceedance curve of SW input and output and GW input and output at the various scenarioes

In Scenario no. 1 of table 4, in which accessible SW (input) is considered $25 \%$ in long term average $(262 \mathrm{MCM})$, it is revealed that the output is equal to the input to some extent of accessible SW.

\begin{tabular}{|c|c|c|c|c|c|c|c|c|c|c|c|c|}
\hline & \multirow{2}{*}{\multicolumn{2}{|c|}{ Normal position }} & \multicolumn{10}{|c|}{ scenarioes for dam failure } \\
\hline & & & \multicolumn{2}{|c|}{ scenarioe-1 } & \multicolumn{2}{|c|}{ scenarioe- 2} & \multicolumn{2}{|c|}{ scenarioe-3 } & \multicolumn{2}{|c|}{ scenarioe-4 } & \multicolumn{2}{|c|}{ scenarioe-5 } \\
\hline & input & $\begin{array}{l}\text { out } \\
\text { put }\end{array}$ & input & $\begin{array}{l}\text { out } \\
\text { put }\end{array}$ & input & out put & input & out put & input & out put & input & out put \\
\hline GW & 432 & 374 & 412 & 448 & 412 & 328 & 412 & 248 & 412 & 248 & 412 & 248 \\
\hline SW & 222.6 & 188 & 71 & 71 & 79 & 79 & 118 & 89 & 131 & 89 & 170 & 89 \\
\hline $\begin{array}{c}\text { Total } \\
\text { Water }\end{array}$ & 654.6 & 562 & 483 & 519 & 491 & 407 & 530 & 334 & 543 & 334 & 582 & 334 \\
\hline Income & 3011 & 4064 & 0 & $\begin{array}{c}227 \\
5\end{array}$ & & 2440 & & 2592 & & 2592 & & 2592 \\
\hline \multirow{2}{*}{\multicolumn{3}{|c|}{ Remark }} & \multicolumn{2}{|c|}{$\begin{array}{c}\mathrm{x}_{2} \text { input }=0.25^{*} \\
262 \\
\end{array}$} & \multicolumn{2}{|c|}{$\mathrm{x}_{2}$ input $=0.30 * 262$} & \multicolumn{2}{|c|}{$\mathrm{x}_{2}$ input $=0.45 * 262$} & \multicolumn{2}{|c|}{$\mathrm{x}_{2}$ input $=0.50 * 262$} & \multicolumn{2}{|c|}{$\begin{array}{c}\mathrm{x}_{2} \text { input }=0.65 * 26 \\
2 \\
\end{array}$} \\
\hline & & & 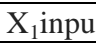 & & Jera & tim & $x_{3}$ & re const & and & me equal & Tormal & sition \\
\hline
\end{tabular}

Table 4. Comparing the allocation of the optimized SW and GW before and after the dam failure

However, GW acts differently. the consumption of GW is more than the input amounts. this result shows that after DF conditions it is necessary to use the GW more than other kinds of water in order to protect the income level of agriculture crops. As an example, consumption of GW in scenario no. 1 of table 4 is equal to 448 M.C.M, $9 \%$ more than long term average which is 412 M.C.M. In other words, after DF conditions consumption of water AS from GW reservoirs is increased (Fig. 3).

\begin{tabular}{|c|c|c|c|c|c|c|c|}
\hline \multirow{5}{*}{ 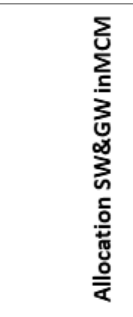 } & \multirow{2}{*}{$\begin{array}{l}500 \\
400 \\
300\end{array}$} & \multicolumn{5}{|c|}{ 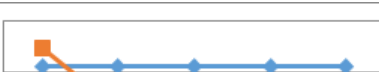 } & \multirow{8}{*}{ scenario no } \\
\hline & & \multicolumn{5}{|c|}{$\longrightarrow$} & \\
\hline & 200 & \multirow{2}{*}{\multicolumn{5}{|c|}{ 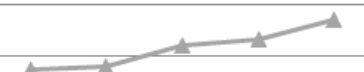 }} & \\
\hline & 100 & & & & & & \\
\hline & 0 & 1 & 2 & 3 & 4 & 5 & \\
\hline \multicolumn{2}{|c|}{$\leadsto$ GW In put } & 412 & 412 & 412 & 412 & 412 & \\
\hline \multicolumn{2}{|c|}{$--G W$ out Put } & 448 & 328 & 248 & 248 & 248 & \\
\hline \multicolumn{2}{|c|}{- SW In put } & 71 & 79 & 118 & 131 & 170 & \\
\hline
\end{tabular}

Figure 3. Exceedance curve of GW output at the different snarioes of DF

Considering the results of table 4 and comparing scenarios 3,4 , and 5 with scenarios 1 and 2, it is clear that the income in AS is directly dependente on the amount of water sources consumption, and this acts as a limiting agent.

In this study, a chance constraint linear programming optimization was applied to use dummy variable technique for the estimation of agriculture sector income (or consumption) function for five scenarios, predetermined in the possible amount of accessible surface water. This optimization method is also used in order to estimate agriculture crops production function in downstream of the dam in the critical status of dam failure. The objective function of the model was set to maximize the income function of the AS region with the accessible surface water and groundwaters sources. It also optimizes crops production before and after the dam failure by using dummy variable regression models. These models politicize the amount of agriculture crops and assume other production factors are fixed in order to the optimization water supply for irrigation. An appropriate method for revealing optimized accessible surface water in famine or after the dam failure is Applying mentioned technique in a linear programming model that maximizes the objective function with definition of different scenarios. Considering the proposed results in this study and the comparison between them and previous studies indicated that this technique describes the effects of descriptive and qualitative factors such as culture and continental situation in addition to the effects of quantitative factors. 
The results of linear programming optimization showed that the real consumption of surface water and groundwaters sources in the normal status of dam operations has not been in optimum and AS income is $34 \%$ less than the optimum as a result of nonoptimized usage of production factors especially accessible water sources. Regarding the scenarios no. 3, 4 and 5, in which accessible surface water has been considered more than $30 \%$ on long term average, it is observed that after assuming dam failure, the allocation of optimized surface water, even in the best possible accessible surface water amount, is independent of the input and has a fixed amount. In other words, due to the lack of a dam reservoir after dam failure, we cannot use the accessible SW amounts for AS.

In Scenario no.1, in which accessible surface water is considered equal or less than $25 \%$ long term average, shows that to some extent of accessible surface water, the output is equal to input. However, the consumption of groundwaters is neccessarily more than the input in order to protect income level of agriculture crops after dam failure conditions. As explained, scenario 3 would be the best amongst scenarios 1,2, 4 and 5 for planning and management of all crops having the least risks of crop damage. It also considers larger numbers of landholders benefitted from greater cultivated area and the subsequent higher job opportunities for laborers

According to the obtained results, it will be clear that the income in agriculture sector is directly dependente on the con sumption amount of water sources, and is a limiting factor. The results also show that the use of developed model is not suitable for the production of agriculture crops function. However it can be useful for programming and predicting the profits and income of agriculture sector. Finally, this approach can be used to study the application efficiency of irrigation and the determination of optimal thresholds of deficit irrigation for major crops grown in the project area to maximize water productivity.

\section{References}

Alok, K.P., 2014. Measuring Energy Intensity and Elasticity in India, A DummyVariablea Approach for Unit LevelHouseh. Jindal Journal of Business Research, 3(1\&2), pp.77-92.

Ashofteh, P.S., Rajaee, T., Golfam, P., 2017. Assessment of Water Resources Development Projects under Conditions of Climate Change Using Efficiency Indexes (EIs). Water Resour Manage, 31, pp.3723-3744

Christer, N., Catherine, A., Reidy, M.D., 2005. Fragmentation and Flow Regulation of the World's Large River Systems. Science, 308, pp.405-407.www.sciencemag.org (15 April 2005).

Christina, T.,Susan, R., 2016. Planning and implementing small dam removals: lessons learned from dam removals across the eastern United States. Water Resource Managment, 2, pp.489493.

Doorenbos, J., KASSAN, A. H.,1979. Yield response to water. Roma, FAO. 193p.
English, M.J., NUSS, G.S., 1982. Designing for deficit irrigation.Journal of the Irrigation and Drainage Engineering, 08(02), pp91-106.

English, M.J., NUSS, G.S., 1982. Designing for deficit irrigation.Journal of the Irrigation and Drainage Engineering, 08(02), pp91-106.

Frizzone, R.D., Coelho, D., Dourado, N., 1997. Linear Programming Model to Optimize the Water Resource Use in. Irrigation Projects:an Application to the Senator Nilo Coelho. Sci agric Piracicaba, 54, pp.136-148.

Ghahraman, B., Sepaskhah, A.R., 2004. Linear and Non linear optimization model for allocation of limited water supply.Irrig Darin Jornal, 53(3), pp39-34.

Hargreaves, G.H., Samani, Z.A., 1984. Economics considerations on deficit irrigation.Journal of the Irrigation and Drainage Engineering,10(4), pp.343-258.

Hasan,S ., Mohammad, F.A., 2015. Linear Programming Model to Optimize Water Supply and Cropping Area for Irrigation A Case Study for Kalihati.Global Journal of Researches Engineering: G Industrial Engineering, 15 (2 ), PP.19-24.

Hassani, N.,Yadollahi, P., Mortazavi, A., 2017. Farmers' Perception of the Seriousness of the Declining Groundwater Volume and their Reactions to Mitigation of its undesirable Outcomes. Journal Management System, 10 (Issue 34), Page 110 .

HSPD., 2011. Estimating Economic Consequences for Dam Failure Scenarios. Homeland Security Presidential Directive (HSPD), USA, pp.1-45.

Huai, Z.u., Jiang, H., Zhi, P.W., 2013. Optimizationof reinforcement strategies for dangerous dams considering timeaveraged system failure probability and benefit-cost ratio using a life quality index. Natural Hazards, 65, PP.799-817.

Jonkman, S.N., Vrijling, J.K.,Vrouwenvelder, A., 2008. Methods for the estimation of loss of life due to floods: a literature review and a proposal for a new method. Natural Hazards, 3, PP.353-389.

Kassahun, B.,Tena, A., Megersa, O., Dinka, S., 2014. Optimizing Reservoir Operation Policy Using Chance Constraint Nonlinear Programming for Koga Irrigation Dam, Ethiopia. Water Resour. Manag, 28, PP.4957-4961.

Kumar, D.N., Raju, K.S., Ashok, B., 2012. Optimalreservoir operation for irrigation of multiple crops using genetic algorithms. ASCE J Irrig Drain Eng, 132(2), pp.123-129.

Michael, L. D., Gary, H.M., 1992. Predicting Loss of Life in Cases of Dam Failure and Flash flood. RiskAnalysk, 13(2),PP193-204.

Palacios,V. H., 1976. Strategies to improve water management in Mexican irrigation districts: A case study in Sonora. Tucson, 197p. Thesis (Ph.D.) the University of Arizona,USA. 
Rao, S.S., 1984. Optimization Theory and Application Second edition. John Wiley and Sons, IEEE,PP1247-1248.

The American Statistician, 2012. Use of Dummy Variables in Testing for Equality Between Sets of Coefficients in linear Regressions: A Generalization. The American Statistician City University of New York, New York, USA. Regressions: A Generalization. The American Statistician City University of New York, New York, USA.

Yavary, G.R., Sashvary, N., 2005. Determining surface and subsurface water productivity in the agriculture sector of Iran. Agriculture Economy \&development, 76, pp.167-181.

U.S.Water Resources Council, 2012. Economic and Environmental Principles and Guidelines for Water and Related Land Resources Implementation Studies, U.S. Government Printing Office, Washington, USA. 